\title{
DERECHO ELECTORAL
}

\section{Medio siglo fructífero. Los cincuenta años de la Escuela de Ciencias Políticas*}

\author{
Constantino Urcuyo Fournier**
}

\section{f}

Nota del Consejo Editorial

Recepción: 29 de octubre de 2018.

Revisión, corrección y aprobación: 7 de noviembre de 2018.

Resumen: Recorrido por los orígenes de la Escuela de Ciencias Políticas de la Universidad de Costa Rica; inicia por el contexto sociopolítico en que nace la escuela, para luego analizar los logros y las transformaciones en sus cincuenta años de existencia.

Palabras clave: Ciencias políticas / Sociología política / Políticos / Enseñanza superior / Universidades públicas.

Abstract: The article presents a review of the origins of the School of Political Sciences of the University of Costa Rica. It begins with the socio-political context in which the school is born. Then, it goes on to analyzing the accomplishments and transformations of its fifty years of existence.

Key Words: Political sciences / Political sociology / Politicians / Higher education / Public universities.

\footnotetext{
* Conferencia dictada el 27 de agosto de 2018 en el marco de la celebración del 50 aniversario de la Escuela de Ciencias Políticas de la Universidad de Costa Rica.

** Costarricense, politólogo, correo constant@racsa.co.cr. Director del Centro de Investigación y Adiestramiento Político Administrativo, profesor universitario. Tiene un doctorado en Derecho de la Cooperación Internacional de la Universidad de Bordeaux y un doctorado en Sociología Política de la Universidad de París.
} 


\section{DERECHO ELECTORAL}

\section{INTRODUCCIÓN}

Un ciudadano de otro país quedaría asombrado si lo llevan a una unidad académica y le explican que de esas aulas han surgido la primera mujer presidenta, muchos diputados, varios ministros, embajadoras, magistrados de la Corte suprema, incluido su actual presidente, y también magistrados electorales. Y si adicionalmente le señalan que otros presidentes ejercieron la docencia en sus aulas, quedaría doblemente sorprendido.

Tal vez su primera conclusión sería que estaba ingresando a la escuela de cuadros de la clase política costarricense, profundamente impresionado por el hálito de poder que transpiraba aquella institución.

Sin embargo, intrigado por el fenómeno, buscaría explicaciones y tendría que ir a los orígenes de aquel espacio universitario para preguntarse por las razones de su gran influencia sobre la sociedad.

\section{SOCIOLOGÍA DEL CONOCIMIENTO}

En este recorrido explicativo su primer instrumento sería recurrir a la sociología del conocimiento, para la cual el pensamiento no tiene una existencia eterna, en sí mismo, ni es invención de individuos aislados.

Esta sociología nos lleva al estudio de la relación entre el pensamiento y el contexto social del que proviene, así como de los efectos que las ideas tienen sobre las sociedades. También busca comprender el sentido y los papeles de las diversas formas del pensamiento, sus prácticas y representaciones.

Karl Marx inaugura este acercamiento a las bases sociales del pensamiento cuando afirma que "no es la conciencia del hombre la que determina su ser sino, por el contrario es el ser social lo que determina su conciencia" (1859, p. 2).

Esta idea pululaba en el ambiente de un siglo XIX, marcado por la industrialización y las revoluciones políticas, Max Scheler (Sociología del saber, 1935), Emile Durkheim (La División del trabajo social, 1893) y Karl Manheim con su famosa Ideología y utopía, publicada en 1929 inauguran el tratamiento académico del tema.

Luego Peter Berger, Thomas Luckman y muchos otros, se sumarán al desarrollo de este enfoque. 


\section{DERECHO EIECTORAL}

Para Durkheim lo importante era precisar cómo el pensamiento conceptual, la lengua y la lógica pueden estar influenciadas por el entorno sociológico del que surgen.

Pero ¿qué tiene que ver todo esto con la celebración del medio siglo de existencia de la Escuela de Ciencias Políticas? La explicación es simple y compleja a la vez. Tenemos que explicarnos por qué surgimos y para ello es inevitable que analicemos el contexto sociopolítico e histórico en el cual nacemos. Muchos de sus fundadores ya han partido, y somos pocos los que retenemos aspectos parciales de la memoria de esos años y su evolución posterior.

Hoy me han pedido que recuerde y recordar es también explicar e interpretar acontecimientos que me tocó vivir como estudiante, profesor $y$, en alguna oportunidad, como director de esta unidad académica durante seis años.

Enseñar es fundamentalmente transmitir conocimientos y estos son interpretaciones, lecturas de la realidad que nos circunda, lectura que transita por nuestra interpretación subjetiva de hechos sociales que nunca son puros y duros. Fijar un curriculum para estudiar un campo de la realidad es seleccionar representaciones, manejar ideas, lenguaje y lógicas.

\section{El CONTEXTO}

Interpretar el origen y evolución de nuestra escuela es remitirnos primero al contexto de su creación y luego a los entornos posteriores que rodearon su evolución.

1-Un primer elemento que nos ayuda a explicar es la reforma universitaria de 1957 que transformó la estructura universitaria y alejó al pensamiento de las visiones normativas de una cierta filosofía política (la ciudad ideal).

La enseñanza de la filosofía se transformó, ingresaron al país filósofos alejados del tomismo católico tradicional como Constantino Láscaris, de amplia cultura filosófica, interesados en la duda y no en la doctrina; la homogeneidad ideológica del cafetal se estremeció.

Paralelamente, empieza a surgir el interés y práctica por las ciencias sociales como análisis concreto de la estructura social, y regresan del extranjero sociólogos como Eugenio Fonseca Tortós y José Luis Vega Carballo que introducen a Max Weber y a Herbert Marcuse. 


\section{DERECHO ELECTORAL}

Igualmente, hay que señalar que en la comisión de creación de la escuela estaba Alfonso Carro, que había estudiado en España y se decantaba por la teoría del estado de Herman Heller, teórico alemán que se había enfrentado en los años treinta al nazi Carl Schmitt y al formalista Kelsen.

Tuve oportunidad de llevar su curso y pude constatar el rigor teórico del libro, así como el escándalo de abogados litigantes y de liberales ingenuos, quienes acusaban a Carro de comunista por afirmar que el Estado era la organización y la activación autónomas de la cooperación social territorial. Para la izquierda aquella definición ocultaba el carácter de clase del Estado; lo cierto es que las enseñanzas de Carro agitaron las aguas y probablemente llevaron a considerar que era necesario apartar el estudio de la política de las apolilladas definiciones normativas y doctrinarias.

La escuela en el mediano plazo se apartó de la Facultad de Derecho e ingresó a la corriente de las Ciencias Sociales. Todavía no dejo de lamentarme que Relaciones Internacionales y Administración Pública existan separadas de las Ciencias Políticas.

2-El otro elemento, relacionado con la historia de las ideas, es el auge del marxismo en Occidente, vinculado al estructuralismo (Althusser, 2011), pero también al combate ideológico de la Guerra Fría.

En Costa Rica el partido comunista luchaba contra su ilegalización, fruto de la Guerra Civil del 48, aunque su apego a los dogmas soviéticos les impedía la crítica del totalitarismo estalinista.

El regreso de pensadores marxistas como Rodolfo Cerdas, Edelberto Torres y Daniel Camacho permite la discusión académica de este pensamiento, fruto de la economía política inglesa, la filosofía clásica alemana y las luchas políticas del socialismo fráncés. Contrariamente a lo que pensaban algunos entonces, el marxismo era hijo auténtico de la cultura occidental.

Por esa época también regresaron al país Rodrigo Madrigal y Manuel Formoso, quienes habían vivido de cerca la revolución del Mayo francés y trajeron consigo las inquietudes y visiones que agitaban el pensamiento en los centros metropolitanos europeos. El liberalismo y la socialdemocracia criollos debían enfrentar ahora una dura competencia en el seno de la universidad.

3-La circunstancia histórica del ingreso de una generación de jóvenes que habíamos nacido después de la Guerra Civil de 1948 es también un factor 


\section{DERECHO ELECTORAL}

importante. Una nueva generación que no había vivido la conflictiva y rica década de los años cuarenta empieza a cuestionarse el modelo implantado por el hegemónico PLN, a señalar sus insuficiencias y a buscar un nuevo proyecto histórico más allá del caudillismo figuerista. El Manifiesto de Patio de Agua (1968) marca el inicio de procesos de disidencia ideológica al interior del PLN.

Por otra parte, profundas modificaciones socioculturales apartaban a los jóvenes de una cultura política rígidamente anclada en los acontecimientos de 1948 y preñada del revanchismo de los vencedores.

4-Las transformaciones socioeconómicas fueron también importantes durante la década de los años sesenta. El monocultivo cafetalero llegaba a su fin y la industrialización liviana, promovida por el PLN, se afianzaba a pesar de la oposición de las elites cafetaleras dominantes en el pasado. Surgiría una nueva elite de industriales, vinculada al Mercado Común Centroamericano, protegida por el Estado y muy activa políticamente.

La urbanización había pasado de $33,5 \%$ en 1950 a 54,61\% en 1963 y alcanzaría el 60,84\% en 1973.

Pensar estos actores de cambio en las actividades productivas, el empleo diversificado y la vida en centros urbanos nos hace llegar a la conclusión de que importantes factores que favorecieron la movilización social estaban presentes ya en el sistema social. Factores que se expresaran con fuerza en la década posterior en la lucha contra la explotación del aluminio en el Valle del General y la gran movilización contra la multinacional ALCOA, bautizo político de mi generación.

5-Dinámicas regionales, con el incremento de la represión somocista en Nicaragua y el intento de crear un Consejo Superior de Defensa Centroamericano (CONDECA), para hacer frente a la movilización guerrillera en Guatemala y al naciente FSLN en Nicaragua, nos llevaron a los estudiantes a lanzarnos a las calles y a denunciar los esfuerzos de algunos sectores para promover la militarización en Costa Rica, la conciencia se agitó al ritmo de las luchas político-sociales.

El intento del Che Guevara por transformar la cordillera de los Andes en la Sierra Maestra de América fracasó, pero su figura se transformó en un ídolo para generaciones de jóvenes que luchaban contra las dictaduras, el militarismo y la dominación externa. 


\section{DERECHO EIECTORAL}

6-La dinámica mundial expresada en el rechazo a la guerra de Vietnam y en la invasión a Checoeslovaquia desató agudas discusiones entre quienes se oponían a la dominación externa, pero querían un socialismo a la checa, con rostro humano, y no asentado sobre los tanques soviéticos, la sangrienta represión de José Stalin y la doctrina de la soberanía limitada de la gerontocracia soviética.

7-Paralelamente, la Iglesia católica experimentaba las consecuencias del Concilio Vaticano II y curas rebeldes como Javier Solís, en asocio con la Juventud Universitaria Católica expresaban un nuevo entusiasmo por la Doctrina Social de la Iglesia desafiando a una jerarquía ultraconservadora, liderada por un arzobispo encerrado en un minicastillo, con ínfulas medievales.

\section{El Reflejo}

Toda esta efervescencia social se reflejará en el grupo de intelectuales que funda la Escuela de Ciencias Políticas, el mundo estaba agitado en proceso de cambio, era necesario pensarlo de otra manera y hacerlo sistemáticamente más allá del pensamiento tradicional.

Aquí es donde vuelve a cobrar importancia mi señalamiento inicial sobre la necesidad del abordaje desde la perspectiva de la sociología del conocimiento, esta creación intelectual y académica debe ser interpretada como un fenómeno social, cuya elaboración estuvo influenciada por circunstancias sociopolíticas concretas.

Era imperativo pensar los partidos cuando el partido hegemónico presentaba sus primeras fisuras, era necesario reflexionar sistemáticamente sobre la vida internacional, cuando la Guerra Fría llegaba a nuestras costas, por la guerrilla y la ayuda de Somoza a la invasión a Bahía de Cochinos. Era impensable no abordar con espíritu agudo la Guerra Fría cuando hacía seis años la humanidad había estado al borde del holocausto nuclear.

Las mismas creencias religiosas se modificaban y se transformaban, los papas Juan XXIII y Paulo VI reformulaban la doctrina social de la Iglesia, acciones que no repercutían sobre una jerarquía costarricense sorda a los aires del cambio.

El estado de bienestar empezaba a mostrar limitaciones de índole burocrática, expresándose en lo que Rodolfo Cerdas llamó un árbol frondoso 


\section{DERECHO EIECTORAL}

con raíces económicas muy débiles y hegemonizado por una burguesía burocrática.

Por otra parte, el ingreso de nuevas élites al sistema político (intelectuales e industriales) motivó el estudio de la declinante elite tradicional cafetalera, reflejado en la obra de Samuel Stone sobre la Dinastía de los Conquistadores, y en su ejercicio posterior como director de esta escuela, dejando una huella indeleble sobre nuestra disciplina y nuestra formación intelectual.

\section{a. INFLUENCIA FRANCESA}

La impronta de Stone se manifestó de manera importante sobre la evolución de nuestra escuela, pues bajo su guía, toda una generación de profesores partimos a París, Rodolfo Cerdas, Jorge Urbina, Paco Barahona, Nelson Gutierrez y quien les habla nos fuimos a obtener doctorados y luego nos reintegramos a la vida académica. También nos trajimos a Cristina Eguizábal quien se hizo tica y hasta embajadora en Italia. De todos ellos soy el último de los mohicanos. La influencia francesa ha sido muy importante en la evolución de esta escuela.

Es importante aquí agregar una reflexión particular, pero que tiene consecuencias teóricas y prácticas importantes. Desde el inicio nos definimos como Escuela de Ciencias Políticas y no de Ciencia Política. Ello supone que todas las ciencias humanas pueden tener una dimensión política, que el estudio sistemático de la política no releva de una disciplina particular, sino que la política y lo político se pueden estudiar desde la historia, la economía, las relaciones internacionales, la sicología o la sociología política. Nuestro curriculum actual sigue expresando esta visión con su énfasis en la transdisciplinareidad.

En otras latitudes esto no ocurre así, la política se puede estudiar como Estudios Políticos, como Gobierno (centrada en lo político, en el aparato del Estado), pero también como ciencia autónoma con metodología propia. Esta es una discusión interesante, desde el punto de vista teórico, pero volvamos a la historia de nuestra escuela y de su contexto.

\section{b. AlcoA}

La década de los años setenta se inaugura en Costa Rica con gran efervescencia política. En abril de ese año se produce la gran manifestación contra ALCOA (Aluminum Co. of America), la cual no es sino un reflejo de 


\section{DERECHO EIECTORAL}

todos los procesos que hemos comentado antes. Una nueva generación hacía su ingreso a la política, aunque no a lo político, eso vendría después.

También es de recordar que Costa Rica establece relaciones con la URSS en esos años, lo que genera la erupción de una extrema derecha intransigente, liderada por el Movimiento Costa Rica Libre y hasta rumores de golpe de Estado que el presidente Figueres logra desarticular en Washington gracias a la intervención de políticos demócratas progresistas como Lawrence Harrison y Ted Kennedy.

La rebelión estudiantil articulada con el apoyo de otros sectores sociales es a su vez el preludio de acontecimientos que conmoverán la vida pública durante toda la década y concluirán con la gran crisis económica de inicios de los años ochenta.

\section{c. Cae Somoza}

La dictadura de Somoza, eje dominante del autoritarismo militar centroamericano, se comienza a tambalear en 1974 con el asalto de la casa del ministro Chema Castillo. EI FSLN opera desde Costa Rica para poner fin a una satrapía que se anima a bombardear el territorio costarricense, pero encuentra una respuesta enérgica y valiente de Rodrigo Carazo y el pueblo costarricense, apoyados por Carlos Andrés Perez y Omar Torrijos.

En la universidad y en la escuela, la discusión giró en torno a la democracia, la democracia ideal versus la democracia real. Democracias electorales rápidamente construidas (El Salvador) versus el imaginario de la democracia popular que guardaban en su mente quienes pensaban que en Nicaragua estaba a la orden del día el advenimiento de una revolución social y de una democracia socialista a imagen y semejanza de las democracias populares del bloque socialista liderado por la URSS.

En lo que respecta a Nicaragua, la discusión fue compleja, pues mientras algunos esperábamos una revolución política que sustituyera a la dictadura con una democracia representativa y abriera la ruta para reformas sociales profundas; otros querían la revolución social desde el inicio.

Todos conocemos los resultados de ese proceso, ni revolución política, ni revolución social, tan solo el nacimiento de otra forma de dictadura sangrienta, disfrazada de socialismo y cristianismo. 


\section{DERECHO EIECTORAL}

En lo que respecta a Centroamérica, una vez terminadas las guerras hemos asistido a formas de democracia electorales incompletas, híbridas, desiguales socialmente y que han evolucionado de manera diferente pero que tienden hacia formas nuevas de autoritarismo como es el caso de Honduras o de populismo mediático como en Guatemala.

El proceso de pacificación de Centroamérica tuvo un impacto en nuestro curriculum, pues llevó a reformular los cursos con miras a dar mayor atención a la realidad centroamericana y a las técnicas de negociación política.

\section{MAS SOCIOLOGÍA DEL CONOCIMIENTO}

Pero volvemos a la sociología del conocimiento donde la guerra, los proyectos revolucionarios y la pacificación subsiguiente condicionaron el pensamiento, la reflexión universitaria. Se inició una nueva etapa en nuestra práctica y reflexión. El marxismo no desapareció, pero sí el leninismo práctico interesado en la toma del poder. La lectura de los autores de la Escuela de Frankfurt mantuvo un pensamiento crítico vigente sobre las limitaciones del capitalismo y las insuficiencias de la democracia liberal.

La revolución conservadora en las metrópolis y el Consenso de Washington obligaron a lecturas críticas sobre el neoliberalismo y la globalización, necesarias, ayer como hoy; pero no realizamos una reflexión a fondo sobre las causas y consecuencias de la implosión de la Unión Soviética. Muchos siguieron añorando el socialismo ideal y no nos adentramos en las características y dinámica del socialismo realmente existente.

La administración Reagan y la invasión de Panamá (1989) significaron una reafirmación de la tradicional Doctrina Monroe, atenuadas después por un periodo alargado de no involucramiento militar en la región, pero nos ha hecho falta una reflexión más profunda sobre las relaciones interamericanas, sobre todo luego de la renuncia de esta por Obama y Kerry y su reafirmación reciente por la administración Trump (Rex Tillerson y Mike Pompeo).

La llegada de los años noventa nos sorprenderá con una transformación de época en la historia de la humanidad, la desaparición de la URSS inauguró una nueva fase de la política internacional que todavía no concluye. 


\section{DERECHO ELECTORAL}

Pero regreso un poco en el tiempo.

Durante la década de los años ochenta me correspondió desempeñarme como director de la escuela por seis años y recuerdo las discusiones de entonces. Algunos querían transformar la escuela en incubadora de cuadros para la revolución, otros en espacio para la formación de cuadros tecnocráticos partidarios y los aislacionistas en convento docente para el cultivo esotérico de la política, casi como ciencia oculta, dedicada exclusivamente a la docencia, sin contaminación alguna con la política práctica.

En aquel entonces dediqué mi acción a mantener el pluralismo; el marxismo debía y debe ser estudiado, es una poderosa crítica del capitalismo y un valioso método de análisis (la contradicción) de la realidad social. Sin embargo, no pude atender las demandas de algunos que exigían descartar a Weber y sustituirlo por Lenin, quien también debe ser leído con atención por el que estudie la sociología de la revolución.

Mantener una escuela dedicada exclusivamente a formar tecnócratas al servicio del sistema tampoco era posible, la universidad no solo debe ser espacio de reproducción, sino de renovación y ello implica mantener la criticidad entendida como la superación de lo dado, de lo constatado y buscar la construcción de lo nuevo, de lo imaginado.

Contribuir al orden social era importante, pero también era imperativo que la escuela produjera un cierto desorden en las certezas de los partidos y actores tradicionales, como dice una frase de un literato francés el orden es fruto de la razón, mientras que el desorden es la delicia de la imaginación (Claudel, 1929).

Toda existencia social supone un cierto orden, pero también la generación de lo nuevo, las fuerzas centrípetas nos encierran, las centrífugas nos aproximan a otros sistemas solares, a lo nuevo, al descubrimiento de nuevas formas de convivencia.

Tuve que luchar contra la tendencia a la pureza, no podíamos permanecer impolutos, virginales, estudiando la política sin rozarnos con ella. Traje a don Pepe Figueres, quien por un semestre dio un seminario especial sobre la Guerra Civil de 1948. Separarnos del objeto de nuestro estudio no era recomendable. 


\section{DERECHO ELECTORAL}

No concibo a un microbiólogo que estudie los virus sin colocarlos bajo el microscopio. Condenar a los políticos u observarlos desde la teoría no era una opción para nuestro desarrollo académico. Por otra parte, no podíamos circunscribirnos a una escuela dedicada a formar docentes, sin ofrecer otras alternativas de desarrollo profesional. Nuestros graduados se han abierto campo no sólo en las jerarquías políticas, sino que también se han destacado como asesores ministeriales, parlamentarios y de empresas.

Fueron años agitados y a veces conflictivos, pero acabaron por decisión propia e inicié mi inmersión en la política práctica al finalizar la década. Hacer política es diferente a estudiar la política.

El hacer puede apoyarse en el conocimiento científico sobre las instituciones y el comportamiento político, lo segundo es materia del arte; la práctica se puede estudiar con el rigor y sistematicidad científica, pero el arte de la política solo se aprende haciendo, practicando, en las asambleas distritales y nacionales, en el ejercicio de la comunicación política, en el diseño y la ejecución cotidianos de las políticas públicas.

Me aparté por cuatro años de la escuela para ser diputado, pero luego regresé a tiempo parcial, así que de 1994 a 1998 no puedo hablarles mucho sobre la escuela, pues esos días los dediqué al aprendizaje de los rudimentos del difícil arte de la política práctica. Sin embargo, esos años coinciden también con el retiro de muchos de los profesores fundadores de la actividad docente y con el ingreso de una nueva generación que ya ha ejercido funciones de dirección de la escuela.

También son años en que empieza a disiparse la hegemonía de los varones tanto en el cuerpo docente como en la dirección de la escuela. Marianela Aguilar asume como primera directora con el inicio del nuevo siglo y luego vendrán las direcciones de Juani Guzmán y de Luz Marina Vanegas.

En los últimos tiempos las prioridades han cambiado, el desarrollo de la maestría, el nacimiento y desarrollo vigoroso del CIEP, la introducción de los temas de género y la práctica de los métodos de investigación cuantitativa me parecen desarrollos altamente positivos.

El cuantitativismo, y no los métodos cuantitativos en sí, podría ser un error que es necesario eludir, dada la particular naturaleza de nuestro objeto de estudio. Practica ese error cuantitativista un reconocido profesor de una escuela de administración de negocios que sostiene que lo que no se puede 


\section{DERECHO EIECTORAL}

medir no existe. La cuantificación es pertinente para la comparación, menos útil para el estudio de las singularidades.

La política no solo debe ser estudiada desde esta óptica, también requiere del análisis diacrónico, de la historia.

La sicología y el sicoanálisis con el estudio de la subjetividad, complementan a la estadística.

La antropología y el estudio de la cultura, junto con la observación participante son también ayudas cruciales para nuestros estudios sobre la política.

No hay unidimensionalidad, sino multidimensionalidad y eclecticismo en nuestros enfoques. Método viene de ruta, de camino en griego, son muchos los caminos que llevan a Roma. La transdisciplinariedad ha sido incorporada con acierto al nuevo curriculum de nuestra escuela.

Un hecho crucial de nuestro presente es el regreso de una nueva generación de profesores jóvenes del extranjero que constituyen el futuro promisorio de la escuela, pues aportan el necesario relativismo que genera vivir afuera. No hay verdades absolutas, tan sólo verdades parciales, sujetas a la duda sistemática y a su eventual refutación.

El desarrollo vigoroso del CIEP en el terreno de los estudios de opinión, con su proyección a nivel nacional, ha tenido un efecto altamente positivo para la reputación de la ECP y podemos esperar que el desenvolvimiento de otras líneas investigativas tenga efectos similares. En la última evaluación para la acreditación este fue uno de los elementos relevantes que contribuyeron al buen posicionamiento de nuestra escuela. El análisis permanente de la coyuntura política es uno de los campos en que todavía debe profundizarse.

El desarrollo de los estudios de género es una de las tareas que nos esperan en el futuro, concordante con la creciente presencia de las mujeres en nuestra comunidad académica.

La más reciente coyuntura política nos lleva a dar más importancia a las políticas macroeconómicas, de seguridad, urbanas y a la intersección de las religiones con la política. Igualmente tendremos que profundizar sobre el multipartidismo, la fragmentación parlamentaria y el sistema electoral, con miras a mejorar la gobernanza del sistema político. 


\section{DERECHOEIECTORAL}

El nacimiento de un mundo multipolar y policéntrico nos obliga a la reflexión intensa sobre la política internacional, reflexión sistémica, pero preocupada por el impacto de las modificaciones de la arquitectura internacional sobre el hemisferio occidental que habitamos.

Como lo he sostenido a lo largo de este discurso la vida social se refleja y debe reflejarse continuamente en nuestras labores. La lucha por la producción que lleve a una prosperidad creciente de los costarricenses es uno de nuestros objetos de estudio. El reconocimiento del conflicto social en el proceso político es imprescindible para entender el proceso de formulación y modificación de las políticas públicas.

La investigación científica rigurosa, fruto de la unión entre el trabajo teórico y el análisis concreto de las situaciones concretas deben ser la guía para los próximos cincuenta años de trabajo de nuestra escuela.

\section{REFERENCIAS BIBLIOGRÁFICAS}

Althusser, L. (2011). La revolución teórica de Marx. Segunda edición. México: Siglo XXI.

Claudel, P. (1929). Le Soulier de satin. París, Francia: [s.n.].

Durkheim, E. (2001)). División del trabajo social. Madrid, España: Ediciones Akal.

Mannheim, K. (2004). Ideología y utopía: Introducción a la sociología del conocimiento. España: Fondo de Cultura Económica de España.

Marx, K. (1859). Prólogo a contribución a la crítica de la economía Política. Recuperado de http://www.biblioteca.org.ar/libros/131839.pdf

Patio de Agua: Manifiesto Democrático para una Revolución Social (1968). Recuperado de https://guiascostarica.info/edel/book/patio-de-aguamanifiesto-democratico-para-una-revolucion-social/ 1968

Scheler, M. (1973). Sociología del saber. Buenos Aires Editorial Siglo XX.

Stone, S. (1975). La dinastía de los conquistadores: la crisis del poder en la Costa Rica contemporánea. San José, C.R.: Educa. 